\title{
Study of Respiratory Symptoms in Farmers Admitted in Tertiary Health Care Institute
}

\author{
Gauri Suhas Kulkarni ${ }^{1}$, Maya Madhav Mortale ${ }^{2^{*}}$, Juhi R. Kadukar² and Abhijit J. Telkhade² \\ 'Associate Professor, Department of Respiratory Medicine, Dr. Vasantrao Pawar Medical College Hospital and \\ Research Centre, Nashik-422003, Maharashtra, India; gaurisuhas@yahoo.com \\ ${ }^{2}$ PG Resident, Department of Respiratory Medicine, Dr. Vasantrao Pawar Medical College Hospital and Research \\ Centre, Nashik - 422003, Maharashtra, India; drmayamortale@gmail.com
}

\section{Abstract}

Background: Farmers have a high prevalence of respiratory symptoms and airway obstruction. Respiratory problems occurs on exposure to various types of farming which are both immunologic and non-immunologic in nature. Aims and Objectives: To study the respiratory symptoms and their association with type of farming in farmers admitted to respiratory medicine ward in a tertiary health care institute. Results: Breathlessness (89.1\%) was the most common clinical feature amongst population. Exposure to organic and inorganic dust, hays, biomass fuel and pesticide were the most common risk factors associated with farming. Nonsmoker farmers also had a more respiratory symptom. Conclusion: Respiratory symptoms are the most common among farmers though smoking is a confounding factor, but it was observed that nonsmoker farmers also developed symptoms.

Keywords: Farming, Non-Smoker Farmer, Respiratory Symptoms

\section{Introduction}

Farmers have a high prevalence of respiratory symptoms and airways obstruction ${ }^{1-3}$. Respiratory problems occur on exposure to various types of farming which are both immunologic and non-immunologic in nature. High percentage of farmers with asthma and respiratory symptoms has severe airways obstruction irrespective of the type of farming.

A significant number of farmers experience respiratory symptoms (e.g., cough with expectoration, chest tightness, sneezing, and wheezing) and/or systemic complaints (e.g. fever, muscle aches, headache) on exposure to farming environment ${ }^{4}$. Inhalation of grain dust has been shown to cause release of histamine and leukotrienes. Release of these inflammatory mediators has been suspected as the cause of acute bronchoconstriction in some farmers, and occurs immediately after exposure to antigens. Symptoms of chronic bronchitis and bronchial asthma have been reported to be more frequent among farmers as compared to a non-farming population. Smoking and animals rearing have been identified as the associated risk factors for symptoms such as breathlessness, cough without any expectoration and wheezing etc. Farming environment is considered favorable for the development of occupational asthma and hypersensitivity pneumonitis ${ }^{5}$.

Exposure to pesticides over a period of time has been associated with increased risk of respiratory symptoms in agricultural activities.

\section{Aims and Objectives}

1. To study the respiratory symptoms in farmers admitted to pulmonary medicine ward in tertiary health care institute. 
2. To study association between type of farming and respiratory symptoms in farmers admitted to pulmonary medicine ward in tertiary health care institute.

\section{Materials and Methods}

Sample size: 120

Conducted at: Tertiary Health Care Institute.

1. Study Design: Retrospective Observational Study

2. Study Setting: Tertiary Health Care Institute

3. Duration of Study: October 2015 to October 2017

4. Study Participants:

1. Sample Size -120

2. Eligibility Criteria

Inclusion criteria:

1. All farmers with respiratory symptoms.

2. Patient willing to participate in research study.

Exclusion criteria:

1. Patients with childhood asthma or other congenital lung diseases.

2. Patients with active pulmonary tuberculosis.

3. Patients having respiratory diseases related to traveling.

4. Patients having history of sputum positive pulmonary tuberculosis in past.

5. Patients not willing to give informed consent.

\section{Methodology}

The present study was conducted in the Department of respiratory medicine of a Medical College. Institutional ethics committee permission was taken prior to study. A total of 120 patients were included at the time of discharge after they satisfy the eligibility criteria. Written informed consent was obtained from all the study participants. Detailed history \& examination were done, and findings were recorded in a predesigned proforma.

\subsection{Statistical Analysis}

All the collected data was entered in Microsoft Excel sheet and then transferred to SPSS software ver. 17 for analysis. Qualitative data was presented as frequency and percentages and analysed using chi-square test. Quantitative data was presented as mean and SD. P-value $<0.05$ was taken as level of significance.

\section{Results}

In this study (Table 1) observed that 51 to 60 years (29.2\%) was the most common age group amongst population followed by 41 to 50 years $(24.7 \%)$ and 31 to 40 years $(24.2 \%)$ with male predominance $(76 \%)$ and female (24\%). Combined farming (65\%) was the most common type of farming which includes all procedures of farming followed by Cutting (13\%), Sowing (9\%) and Grain handling (7\%) and Tilling (6\%) (Figure 1).

Table 1. Age group

\begin{tabular}{|l|l|l|}
\hline Age group & Frequency & Percent \\
\hline 31 to 40 years & 29 & 24.2 \\
\hline 41 to 50 years & 30 & 24.7 \\
\hline 51 to 60 years & 35 & 29.2 \\
\hline 61 to 70 years & 17 & 14.2 \\
\hline more than 70 years & 9 & 7.5 \\
\hline Total & $\mathbf{1 2 0}$ & $\mathbf{1 0 0}$ \\
\hline
\end{tabular}

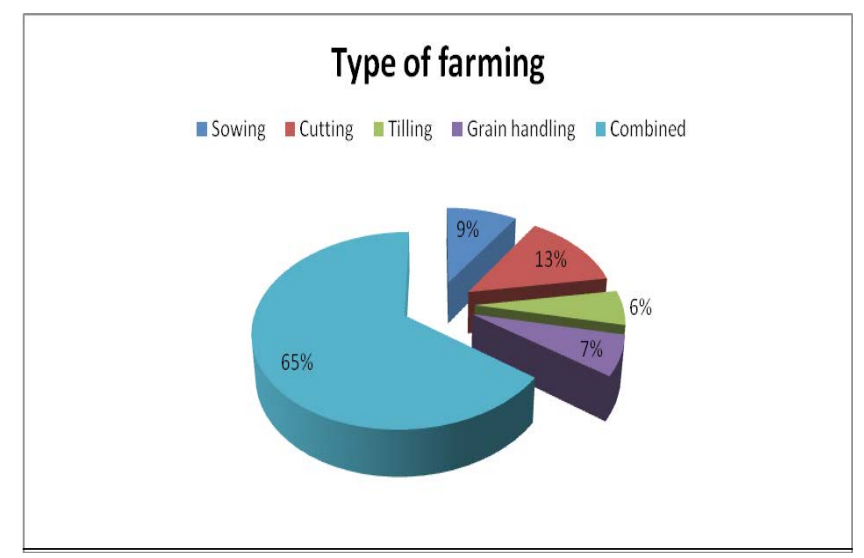

Figure 1. Type of farming. These are not types of farming, but farming procedures. Types may be organic or inorganic farming etc.

Table 2. Duration of farming amongst study population

\begin{tabular}{|l|l|l|}
\hline Duration of farming & Frequency & $\%$ \\
\hline$<10$ year & 16 & 13 \\
\hline $10-20$ year & 41 & 34 \\
\hline $20-30$ years & 53 & 44 \\
\hline$>30$ years & 10 & 9 \\
\hline Total & $\mathbf{1 2 0}$ & $\mathbf{1 0 0}$ \\
\hline
\end{tabular}


20-30 year (44\%) was the most common duration of farming amongst population followed by $10-20$ years $(34 \%),<10$ year $(13 \%)$ and $>30$ years $(9 \%)$ (Table 2 ).

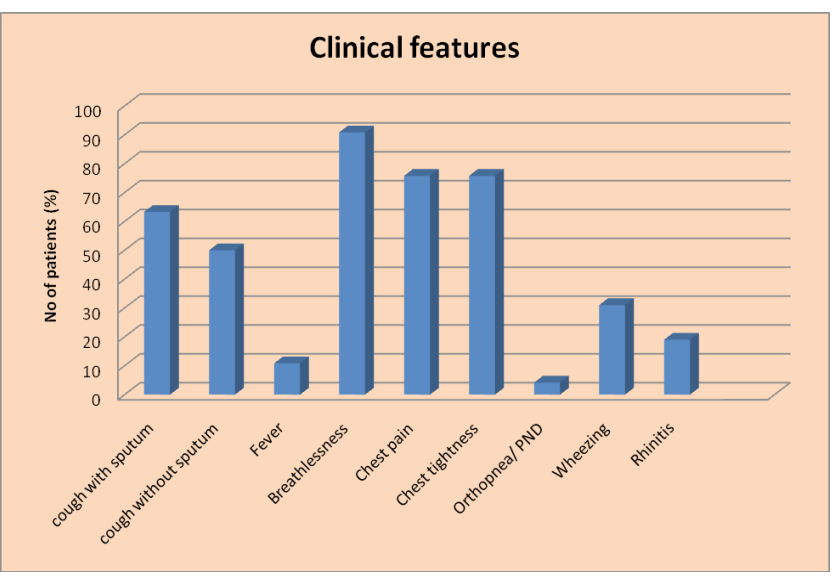

Figure 2. Clinical features.

Breathlessness (90.83 \%) was the most common respiratory symptom followed by Chest pain (75.8\%), Chest tightness (75.8\%), cough with sputum (63.3\%), cough without sputum (50\%), Wheezing (31\%), Orthopnea/PND (4.16\%), Rhinitis (19\%), Fever (10.83\%) (Figure 2). Smoking (38.33\%) was the most common personal habit, nonsmokers (61.67\%) while smokers were $38.33 \%$. followed by alcohol intake (32.5\%), Tobacco chewing (22.5\%) and diabetes (20.8\%) was the most common associated comorbidity.

Breathlessness (89.1\%) was the most common clinical feature amongst population followed by Chest tightness (76.1\%), Chest pain (73.9\%), cough with sputum(67.4\%) and Wheezing (56.5\%) while in nonsmokers and Breathlessness $(91.9 \%)$ was the most common clinical feature followed by, Chest pain (77\%), cough with sputum $(60.81 \%)$ (Table 3$)$.

\section{Discussion}

The study was conducted for the duration of 2 years from October 2015-2017. Farmers have a occupational exposures that may influence their respiratory health in both positive and negative ways. Due to their occupational exposures to hays, grains and animals' farmers have been identified as a group which is at higher risk of respiratory disease than many other occupations ${ }^{6}$. Long-term exposure to organophosphate and carbamate pesticides will lead to inhibition of acetylcholinesterase synthesis from $M_{2}$ muscarinic receptors that results in mucus hypersecretion and airway smooth muscle contraction causing breathlessness, cough and wheeze.

Table 3. Comparison of respiratory symptoms amongst smokers and nonsmokers' farmers

\begin{tabular}{|l|l|l|l|l|}
\hline Clinical features & Smokers & $\begin{array}{l}\text { Non } \\
\text { smokers }\end{array}$ & Total n (\%) & P value \\
\hline cough with sputum & $31(67.4 \%)$ & $45(60.81 \%)$ & $\begin{array}{l}76 \\
(63.3 \%)\end{array}$ & 0.467 \\
\hline cough without sputum & $22(47.8 \%)$ & $38(51.35 \%)$ & $\begin{array}{l}60 \\
(50 \%)\end{array}$ & 0.707 \\
\hline Fever & $8(17.4 \%)$ & $13(6.75 \%)$ & $\begin{array}{l}21 \\
(17.5 \%)\end{array}$ & 0.980 \\
\hline Breathlessness & $41(89.1 \%)$ & $68(91.9 \%)$ & $\begin{array}{l}109 \\
(90.8 \%)\end{array}$ & 0.610 \\
\hline Chest pain & $34(73.9 \%)$ & $\begin{array}{l}57 \\
(77 \%)\end{array}$ & $\begin{array}{l}91 \\
(75.8 \%)\end{array}$ & 0.698 \\
\hline Chest tightness & $35(76.1 \%)$ & $19(25.7 \%)$ & $\begin{array}{l}54 \\
(45 \%)\end{array}$ & 0.0001 \\
\hline Orthopnea/PND & $\begin{array}{l}(2.2 \%) \\
(5.4 \%)\end{array}$ & $\begin{array}{l}5 \\
(4.2 \%)\end{array}$ & 0.389 \\
\hline Wheezing & $26(56.5 \%)$ & $\begin{array}{l}11 \\
(14.9 \%)\end{array}$ & $37(30.8 \%)$ & 0.0001 \\
\hline Rhinitis & $17(37 \%)$ & $\begin{array}{l}6 \\
(8.1 \%)\end{array}$ & $23(19.2 \%)$ & 0.0001 \\
\hline
\end{tabular}


In this study it was observed that 51 to 60 years (29.2\%) was the most common age group amongst population followed by 41 to 50 years $(24.7 \%)$ and 31 to 40 years $(24.2 \%)$ with male predominance. These findings are in agreement with the study conducted by Neice Müller Xavier Faria et al.,, , in which $25 \%$ of study belongs to age group of more than 50 years. Combined farming (65\%) was the most common type of which includes all the procedures of farming followed by Cutting (13\%), Sowing (9\%) and Grain handling (7\%) and Tilling (6\%). This finding is in agreement with the study conducted by D. Behera et al., $\stackrel{8}{=}$ in which Combined farming (66\%) was the most common type of farming followed by Cutting (14\%), Grain handling (8.5\%) and Tilling (6.6\%) and Sowing (4.7\%). It was observed that $20-30$ year (44\%) was the most common Duration of farming amongst population who presented with respiratory symptoms.

Breathlessness (90.83\%) was the most common clinical feature amongst population followed by Chest pain $(75.8 \%)$, Chest tightness $(75.8 \%)$, cough with sputum (63.3\%), cough without sputum (50\%), Wheezing (31\%), Orthopnea/PND (4.16\%), Rhinitis (19\%), Fever (10.83\%). Similarly, in the study conducted by D. Behera et al., it was observed that symptoms of chronic bronchitis have been reported to be more frequent among farmers as compared to a non-farming population $61.67 \%$ populations were nonsmokers while $38.33 \%$. were smokers This finding is in agreement with the study conducted by $\mathrm{D}$. Behera et al.,$\frac{8}{\text { in }}$ which there were a total of 486 farmers with 142 (29.2\%) being smokers (all males) and 344(70.8\%) nonsmokers. Breathlessness (89.1\%) was the most common clinical feature amongst population followed by Chest tightness (76.1\%), Chest pain (73.9\%), cough with sputum $(67.4 \%)$ and Wheezing (56.5\%) while in nonsmokers and Breathlessness (91.9\%) was the most common clinical feature followed by, Chest pain (77\%), cough with sputum (60.81\%) these findings are in agreement with the study conducted by D. Behera et al., $\stackrel{8}{\text {. }}$

\section{Conclusion}

Most of the study population belongs to age group of 51 to 60 years with male predominance. Breathlessness was the most common clinical feature amongst population followed by Chest pain. Combined farming was the most common type of farming. There are various risk factors associated with farming which are responsible for respiratory symptoms in farmers like exposure to organic and inorganic dust, hays, biomass fuel and exposure to pesticide.

Respiratory symptoms are the most common among farmers though smoking is a confounding factor, but it was observed that nonsmoker farmers also developed respiratory symptoms.

\section{References}

1. Husman K, Koskenvuo M, Kaprio J, Terho EO, Vohlonen I. Role of environment in the development of chronic bronchitis, Eur J Respir Dis. 1987; 71(suppl 152):57-63.

2. Saia B, Mastrangelo G, Marcer G, Reggio O. Prevalence and risk factors of chronic respiratory disease in a farming population, Med Lav. 1984; 75:101-09.

3. Dosman JA, Graham BL, Hall D, van Loon P, Bhasin P, Froh F. Respiratory symptoms and pulmonary function in farmers, J Occup Med. 1987; 29:39-43.

4. Matsons C, Swanson MC, Reed CE, Yunginger J W, IgE and IgG mediated immune mechanisms don't mediate occupation related respiratory or systemic symptoms in hog farmers, J Allergy Clin Immunology. 1983; 72:299-304. https://doi.org/10.1016/0091-6749(83)90035-0.

5. Dopico GA, Reddan W, Flaherty D, et al., Respiratory abnormalities among grain handlers, Am Rev Rspir Dis.1977; 115:915-27.

6. Schenker MB, Christiani D, Cormier Y, et al. Respiratory health hazards in agriculture, Am J Respir Crit Care Med. 1998; 158:S1-76 [PubMed]. https://doi.org/10.1164/ ajrccm.158.supplement_1.rccm1585s1.

7. Neice Müller Xavier Faria ILuiz Augusto Facchini II Anaclaudia Gastal Fassa II Elaine Tomasi III, Farm work, dust exposure and respiratory symptoms among farmers, Rev Saúde Pública. 2006; 40(5):1-9.

8. Behera D, Pal D, Gupta D. Respiratory symptoms among farmers in the vicinity of a north Indian city, Lung India. 2005; 22:45-9
How to cite this article: Kulkarni GS, Mortale MM,, Kadukar JR, Telkhade AJ. Study of Respiratory Sympyoms in Farmers Admitted in Tertiary Health Care Institute. MVP J. Med. Sci. 2019; 6(1):84-87. 